\title{
Epimural bacterial community structure in the rumen of Holstein cows with different responses to a long-term subacute ruminal acidosis diet challenge
}

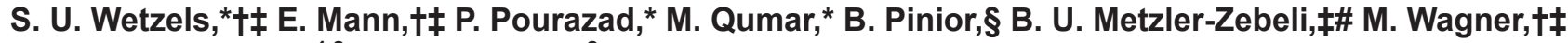 \\ S. Schmitz-Esser, $† \ddagger^{1,2}$ and $Q$. Zebeli* $\ddagger^{2}$ \\ *Institute of Animal Nutrition and Functional Plant Compounds, \\ †Institute for Milk Hygiene, Milk Technology and Food Science, \\ †Research Cluster, Animal Gut Health, \\ §Institute for Veterinary Public Health, and \\ \#University Clinic for Swine, Department for Farm Animals and Veterinary Public Health, University of Veterinary Medicine Vienna, \\ Veterinaerplatz 1, 1210 Vienna, Austria
}

\begin{abstract}
Subacute ruminal acidosis (SARA) is a prevalent metabolic disorder in cattle, characterized by intermittent drops in ruminal $\mathrm{pH}$. This study investigated the effect of a gradual adaptation and continuously induced long-term SARA challenge diet on the epimural bacterial community structure in the rumen of cows. Eight rumen-cannulated nonlactating Holstein cows were transitioned over $1 \mathrm{wk}$ from a forage-based baseline feeding diet (grass silage-hay mix) to a SARA challenge diet, which they were fed for $4 \mathrm{wk}$. The SARA challenge diet consisted of $60 \%$ concentrates (dry matter basis) and $40 \%$ grass silage-hay mix. Rumen papillae biopsies were taken at the baseline, on the last day of the 1-wk adaptation, and on the last day of the 4-wk SARA challenge period; ruminal $\mathrm{pH}$ was measured using wireless sensors. We isolated DNA from papillae samples for $16 \mathrm{~S}$ rRNA gene amplicon sequencing using Illumina MiSeq. Sequencing results of most abundant key phylotypes were confirmed by quantitative PCR. Although they were fed similar amounts of concentrate, cows responded differently in terms of ruminal $\mathrm{pH}$ during the SARA feeding challenge. Cows were therefore classified as responders $(\mathrm{n}=4)$ and nonresponders (n $=4$ ): only responders met the SARA criterion of a ruminal $\mathrm{pH}$ drop below 5.8 for longer than $330 \mathrm{~min} / \mathrm{d}$. Data showed that Proteobacteria, Firmicutes, and Bacteroidetes were the most abundant phyla, and at genus level, Campylobacter and Kingella showed highest relative abundance, at 15.5 and $7.8 \%$, respectively. Diversity
\end{abstract}

Received June 15, 2016.

Accepted November 9, 2016.

${ }^{1}$ Current address: Department of Animal Science, Iowa State University, 3222 NSRIC, 1029 North University Boulevard, Ames, IA 50011.

${ }^{2}$ Corresponding authors: SSE@iastate.edu and Qendrim.Zebeli@ vetmeduni.ac.at analyses revealed a significant increase of diversity after the 1-wk adaptation but a decrease of diversity and species richness after the 4-wk SARA feeding challenge, although without distinction between responders and nonresponders. At the level of the operational taxonomic unit, we detected diet-specific shifts in epimural community structure, but in the overall epimural bacterial community structure, we found no differences between responders and nonresponders. Correlation analysis revealed significant associations between grain intake and operational taxonomic unit abundance. The study revealed major shifts in the 3 dominating phyla and, most importantly, a loss of diversity in the epimural bacterial communities during a long-term SARA diet challenge, in which $60 \%$ concentrate supply for 4 wk was instrumental rather than the magnitude of the drop of ruminal $\mathrm{pH}$ below 5.8 .

Key words: rumen epithelium, subacute rumen acidosis, cattle feeding, amplicon sequencing, bacterial microbiome

\section{INTRODUCTION}

Feeding patterns in dairy cattle have changed over the last decades, in favor of energy- and nutrient-rich concentrates fed at the expense of fiber-rich forages. These dietary shifts have supported high milk yields but raised concerns about compromised rumen function (Zebeli et al., 2012; Boerman et al., 2015). Accordingly, SARA, which is characterized as intermittent drops in ruminal $\mathrm{pH}$, has become a prevalent metabolic disorder in intensively reared cattle (Plaizier et al., 2008). In particular, the microbiological changes associated with SARA have attracted the attention of the SARA research (Khafipour et al., 2011; Plaizier et al., 2012). These changes seem to be essential in the modulation of systemic health in cattle, such as the activation of systemic inflammation and increasing susceptibility to 
other diseases (Plaizier et al., 2008; Zebeli and MetzlerZebeli; 2012; Steele et al., 2016).

In the rumen, bacteria are the predominant microorganisms, being particularly responsible for the fermentation of feeds into short-chain fatty acids (SCFA), which serve as an essential energy source for the host animal (Mackie, 2000). Of the ruminal microbial communities, bacteria in the rumen fluid and those attached to feed particles have attracted considerable research interest, but comparatively less is known about bacteria attached to the rumen wall, commonly known as epimural bacteria. In recent years, a few studies have been published describing the bovine epimural bacterial microbiome (BEBM) using high-throughput sequencing methods (Mao et al., 2015; Liu et al., 2016; Wetzels et al., 2016), but each have shown low sequence similarity between detected phylotypes and best type strain hits. From the host perspective, the BEBM is the first contact between the rumen environment and the rumen epithelium, competing with adherent and putative pathogenic microorganisms (Kamra, 2005; Khafipour et al., 2011). Therefore, it is reasonable to assume that this microbial community may fulfill an important role in protecting the epithelium from harmful microbes by forming a protective biofilm, in particular during challenging microbial growth conditions such as SARA. Khafipour et al. (2011) showed a burst of potentially pathogenic Escherichia coli during SARA, for example. However, the metabolic function of the BEBM is only partially understood, and the overall community structure needs to be evaluated in more detail. Results from earlier studies suggest a role for the epimural bacterial microbiome in the hydrolysis of urea (Fay et al., 1979; Wallace et al., 1979), and direct involvement in oxygen scavenging, responsible for maintaining strict anaerobic conditions (Cheng et al., 1979), as well as tissue recycling (McCowan et al., 1978) and amino acid metabolism (Mao et al., 2015).

Several publications have described microbial changes using different SARA challenge models (Hook et al., 2011; Khafipour et al., 2011; Mao et al., 2013). Current research has shown that dairy cattle respond differently to a concentrate-rich diet. Certain cows do not meet the SARA criteria despite a similar grainrich diet (Humer et al., 2015), although in this study the effect on microbial communities due to different SARA responses of the animals was not determined. In addition, information is lacking about the effect of a long-term continuously induced SARA challenge on the $\mathrm{BEBM}$, and whether differences in SARA responses can be explained by differences in the composition of cows' BEBM. Our study aimed to evaluate the BEBM during adaptation from a forage-based to a concentrate-based diet and after 4 wk of continuous concentrate-based feeding in cows that did or did not have rumen $\mathrm{pH}$ drop in response. We hypothesized that the BEBM composition would shift from the baseline to the adaptation to the SARA challenge, and that it could be distinguished according to the SARA response of the individual cows. We also monitored changes in the BEBM to find putative microbial indicator candidates for SARA.

\section{MATERIALS AND METHODS}

\section{Animals, Diets, and Experimental Design}

A continuous diet-induced SARA challenge experiment was conducted as part of a larger study that investigated long-terms of effects of 2 different models of SARA on the BEBM, with a transient SARA model reported in Wetzels et al. (2016) and a continuous SARA model described here. The experiment was performed with 8 rumen-cannulated $(100 \mathrm{~mm}$ inner diameter; Bar Diamond, Parma, ID) nonlactating Holstein cows (initial BW $710 \pm 118 \mathrm{~kg}$, mean $\pm \mathrm{SD}$ ). Cows were housed together in a freestall barn at the dairy research farm of the University of Veterinary Medicine Vienna in Pottenstein, Austria. The experiment was conducted in 2 separate runs of $7 \mathrm{wk}$ each, with 4 cows tested at the same time in each run. We used a feeding model to induce the continuous and long-term SARA challenge as follows: 2 wk of baseline feeding, followed by 1 wk of gradual adaptation to a $60 \%$ concentrate diet, followed by 4 wk of a continuous SARA challenge with $60 \%$ concentrate.

During the baseline period, cows were fed a forage mix consisting of $50 \%$ grass silage and $50 \%$ second-cut meadow hay (DM basis), and containing 54.4\% DM, $8.4 \%$ ash, $11.3 \% \mathrm{CP}$, and $50.0 \% \mathrm{NDF}$ at a rate of $1.5 \%$ of BW. During the adaptation period and SARA challenge, cows were fed a concentrate mixture in separate and controlled feeding troughs (RIC system; Insentec B.V., Marknesse, the Netherlands) in addition to the forage. The concentrate mixture consisted of barley grain $(33.0 \%)$, wheat $(30.0 \%)$, corn $(15.0 \%)$, rapeseed meal $(17.0 \%)$, dried beet pulp $(3.2 \%)$, calcium carbonate $(0.5 \%), \mathrm{NaCl}(0.3 \%)$, and mineral-vitamin premix for cattle $(1.0 \%)$. During the adaptation period, the concentrate amount was increased by $10 \%$ daily up to $60 \%$, where it remained during the 4 -wk SARA challenge. The SARA challenge diet contained $74.1 \%$ DM, $5.9 \%$ ash, $15.4 \% \mathrm{CP}, 31.8 \% \mathrm{NDF}$, and $45.3 \% \mathrm{NFC}$ (all DM basis), and was fed for $2 \%$ of BW, meeting cows' voluntary feed intake. Fresh water was provided ad libitum. Daily concentrate and forage intake were recorded electronically. Cows that did not consume their planned concentrate allowance were force-fed the residual concentrate through the rumen cannula to en- 
sure the intake of a 60:40 ratio of concentrate to forage during the SARA challenge period.

All procedures were approved by the institutional ethics committee of the University of Veterinary Medicine Vienna in accordance with good scientific practice guidelines and the national authority according to section 26 of the law for animal experiments, Tierversuchsgesetz-TVG 2012 (GZ 68.205/0093-II/3b/2013).

\section{Ruminal pH Measurements, Definition of SARA, and Responses to SARA Diet Challenge}

To monitor ruminal $\mathrm{pH}$, ruminal $\mathrm{pH}$ sensors (smaXtec Animal Care Sales GmbH, Graz, Austria) were manually introduced into the bottom of the ventral rumen in each cow via cannula, as described in Pourazad et al. (2016). The definition of SARA was a rumen $\mathrm{pH}$ below 5.8 for at least $330 \mathrm{~min} / \mathrm{d}$ (Zebeli et al., 2008). Based on their ruminal $\mathrm{pH}$ during the SARA challenge period, cows were classified as responders (RES) and nonresponders (NRES). Cows that developed SARA (as defined above) during the SARA challenge were classified as RES, and cows that did not show a decrease in ruminal $\mathrm{pH}$ during the SARA challenge were classified as NRES.

\section{Rumen Papillae Sampling}

Rumen papillae biopsy samples were taken at the end of the baseline period before concentrate was fed, on the last day of the adaptation phase, and on the last day of the 4-wk SARA challenge. Rumen papillae biopsies were taken from the rumen wall of the ventral sac about $40-50 \mathrm{~cm}$ below the bottom edge of the rumen cannula located in the left fossa paralumbalis, using the method described by Wetzels et al. (2016).

\section{DNA Extraction}

Biopsies were thawed on ice, and genomic DNA was extracted from $0.25 \mathrm{~g}$ of rumen papillae using the PowerSoil DNA Isolation Kit (MO BIO Laboratories Inc., Carlsbad, CA) as described by Wetzels et al. (2016). This method has been evaluated for rumen papillae in our laboratory (Wetzels et al., 2015) and was used so that this data set would be comparable to a previously published data set, belonging to the larger study (Wetzels et al., 2016).

\section{Sequencing, Sequence Processing, and Analysis}

Amplicon sequencing was performed using the Illumina MiSeq sequencing platform (Microsynth AG, Balgach, Switzerland). The V3/4/5 hypervariable re- gion of bacterial $16 \mathrm{~S}$ rRNA genes was amplified using the primer set 341F [5'-CCTACGGGRSGCAGCAG-3'; Zakrzewski et al. (2012)] and 909R [5'-TTTCAGYCTTGCGRCCGTAC-3'; Tamaki et al. (2011)] to generate paired-end reads of $300 \mathrm{bp}$. Microsynth performed a 16S rRNA gene PCR, library preparation, and sequencing was described by Wetzels et al. (2016). Briefly, libraries were constructed by ligating sequencing adapters and indices onto purified PCR products. The Nextera XT Sample Preparation Kit (Illumina Inc., San Diego, CA) was used according to the manufacturer's recommendations. After sequencing, corresponding overlapping paired-end reads were stitched to get an approximate amplicon size of $568 \mathrm{bp}$. Sequence data were analyzed using the mothur software package (http://www.mothur.org/), according to the Illumina MiSeq procedure described by Kozich et al. (2013). Barcode sequences, primer, and low-quality sequences were trimmed using a minimum average quality score of 35, with a window size of 50 bp. In total, 924,305 sequences $(44.7 \%)$ passed quality control, and sequences were randomly subsampled to 40,000 sequences per sample. These sequences were clustered into operational taxonomic units (OTU) with a $97 \%$ similarity cutoff (0.03 distance), and the SILVA SSU reference database version 119 (Pruesse et al., 2007) and RDP trainset (trainset9_032012.rdp.tax) were used for alignment. All OTU with less than 10 sequences were removed $(117,932$ OTU), and a total of 6,339 OTU were used for downstream analysis. We calculated the nonparametric estimates Chao 1 and abundance-based coverage estimator, and the diversity indices Simpson, Shannon, and the Shannon index-based measure of evenness and coverage using the "summary.single" command. Heatmaps were created using JcolorGrid (Joachimiak et al., 2006). We used Explicet version 2.10.5 07/21/14 (Robertson et al., 2013) for Bray-Curtis analysis. We classified the 100 most abundant OTU of all 3 rumen conditions against type strains using the Greengenes database (http://greengenes.lbl.gov; DeSantis et al., 2006).

\section{Quantitative PCR of Universal Bacteria and Key Phylotypes}

Highly abundant OTU (relative abundance greater than 1\%) that showed significant shifts with the SARA challenge were defined as putative key phylotypes for a healthy rumen or for SARA, respectively. The shifts of these phylotypes were confirmed using quantitative PCR (qPCR): DNA samples were assayed in duplicate in a $20-\mu \mathrm{L}$ reaction mixture containing $10 \mu \mathrm{L}$ of $2 \times$ Brilliant III Ultra-Fast SYBR Green qPCR Master Mix (Agilent, Vienna, Austria), $2 \mu \mathrm{L}$ of each primer $(2.5$ 
$\mu M), 5 \mu \mathrm{L}$ of nuclease-free water, and $1 \mu \mathrm{L}$ of DNA template $(2-50 \mathrm{ng} / \mu \mathrm{L})$. Amplification was conducted with 1 cycle at $95^{\circ} \mathrm{C}$ for 3 min and 40 cycles of $95^{\circ} \mathrm{C}$ for $5 \mathrm{~s}$, followed by $20 \mathrm{~s}$ at $61^{\circ} \mathrm{C}$ and $57^{\circ} \mathrm{C}$ for general bacteria and OTU-specific primer-pairs (Supplemental Table S1A; https://doi.org/10.3168/jds.2016-11620), respectively. After all real-time PCR, we completed a melting curve that ranged from $73^{\circ} \mathrm{C}$ to $93^{\circ} \mathrm{C}$, with fluorescence measurements at $1^{\circ} \mathrm{C}$ intervals. The qPCR results were normalized after the reaction and analyzed using the associated software (Stratagene MxPro, QPCR Software, version 2.00, Agilent). We conducted an in-silico PCR against the SILVA database using TestPrime (http:// www.arb-silva.de/search/testprime/) to determine the specificity of the reaction, and found no non-target match for any of the primers designed in this study. We confirmed primer specificity by Sanger-sequencing of the qPCR amplicons produced by each primer pair and by following the MIQE guidelines checklist [Supplemental Table S1B; Bustin et al. (2009)]. The standards for $\mathrm{qPCR}$ were prepared with pooled DNA from all samples as described previously (Wetzels et al., 2016). In each qPCR assay, standard curves (range: $1 \mathrm{e}+3$ to $1 \mathrm{e}+7$ gene copy numbers) were included. Negative controls were included in duplicate.

\section{Statistical Analysis}

To test our hypothesis, data were analyzed for phyla, genera, OTU, and diversity indices using $\mathrm{R}$ software ( $\mathrm{R}$ Development Core Team, 2015; www.r-project.org). We used lmer models [fitting linear mixed-effect models, R-package, lme4; Bates et al. (2015)] to analyze the effects of rumen conditions (i.e., baseline, adaptation, SARA challenge) and affiliation between RES or NRES and the abundance of phyla, genera, OTU, or diversity indices. Beside these fixed effects (time points and RES/NRES), we also used animal $(\mathrm{n}=8)$ and run ( 1 or 2 ) as random effects. Measurements taken on the same animal at different times during the SARA challenge were considered to be repeated measures. We assessed data visually as histograms and checked quantile plots for the normal distribution of residuals and using the Shapiro-Wilk test. We calculated contrast coefficients among the 3 rumen conditions (baseline, adaptation, and SARA challenge) for each phylum, genus, OTU, and diversity index to determine changes in these parameters using a multiple comparison of means (Tukey contrasts). The contrast calculation was implemented in $\mathrm{R}$ using the package multcomp (https://cran.rproject.org/web/packages/multcomp/multcomp.pdf).

Data were presented as means \pm standard error of the mean. Significance was declared at $P \leq 0.05$, and trends were declared at $0.05<P \leq 0.10$. We analyzed the relationship between OTU, average ruminal $\mathrm{pH}$ value, and total concentrate intake with respect to all OTU by performing pairwise Spearman correlations $\left(r_{s}\right)$. In this context, we determined the correlation coefficients (1) between the average ruminal $\mathrm{pH}$ values and all OTU $(\mathrm{n}=6,339)$, and $(2)$ between total concentrate intake and all OTU over all 3 rumen conditions and animals. We also determined the $r_{s}$ between $\mathrm{pH}$ and OTU, and concentrate intake and OTU, for both RES and NRES cows individually. Linear discriminant analysis was computed with OTU that occurred in all rumen conditions ( $\mathrm{n}=1,882$ ), using JMP (version 10.0.0; SAS Institute Inc., Cary, NC). To determine whether the overall BEBM differed between RES and NRES, we performed weighted unifrac with QIIME (http://qiime. org; Caporaso et al., 2010) using the anosim method (test statistic name $\mathrm{R}$, number of permutations 999). We also performed an unpaired $t$-test to detect differences between RES and NRES at OTU level for the 50 most abundant OTU, using R.

\section{Accession Numbers}

Sequencing data are available in the BioProject SRA database (https://www.ncbi.nlm.nih.gov/ bioproject/?term=PRJEB12642) under the accession number PRJEB12642.

\section{RESULTS}

\section{Responses of Ruminal $\mathrm{pH}$}

Data for ruminal $\mathrm{pH}$ and concentrate intake are shown in Table 1. During the baseline period, the duration of ruminal $\mathrm{pH}$ below 5.8 was $0 \mathrm{~min} / \mathrm{d}$ for each of the 8 experimental cows. During adaptation, cows consumed between 6.6 and $8.7 \mathrm{~kg}$ of concentrate/d and ruminal $\mathrm{pH}$ dropped in all cows, but we observed no differences between RES and NRES in either concentrate intake $(P=0.16)$ or daily mean ruminal $\mathrm{pH}(P=0.11)$; minimum ruminal $\mathrm{pH}$ tended to be lower in RES cows $(P=0.09)$. Looking at individual cows (Supplemental Table S2; https://doi.org/10.3168/jds.2016-11620) during adaptation, 3 cows experienced SARA, 4 cows had decreased ruminal $\mathrm{pH}$ but above the SARA threshold of $330 \mathrm{~min} / \mathrm{d}$ of $\mathrm{pH}$ below 5.8 , and 1 cow was well above the SARA threshold. During the SARA challenge, average, maximum, and minimum ruminal $\mathrm{pH}$ were all significantly decreased in RES (mean $\mathrm{pH}=5.8$ ) compared with NRES (mean $\mathrm{pH}=6.4$ ). Indeed, during the SARA challenge, 4 cows experienced SARA and 4 did not, and were classified as RES $(n=4)$ and NRES (n 
$=4$ ), respectively. We found no significant differences related to concentrate intake when comparing RES and NRES during the SARA challenge (Table 1).

\section{Epimural Bacterial Structure}

Amplicons were clustered into 124,271 OTU, of which 117,932 OTU were excluded because they contained fewer than 10 sequences. The remaining 6,339 OTU were used for all further analyses. In total, we detected 18 phyla, Proteobacteria, Firmicutes, and Bacteroidetes being most abundant and accounting for $94.7 \%$ of all sequences (relative abundances of $45.2 \%$, $33.7 \%$, and $15.9 \%$, respectively). Five phyla showed a relative abundance of greater than $1 \%$; Synergistetes $(1.7 \%)$ and Elusimicrobia $(1.2 \%)$ were the fourth and fifth most abundant (Table 2). In total, we found 344 genera, Campylobacter being the most abundant (15.5\% relative abundance), followed by Kingella (7.8\%), Desulfobulbus (4.7\%), and Brachymonas (4.2\%). The 50 most abundant genera (greater than than $0.25 \%$ relative abundance) are shown in Table 3. At the OTU level, the most abundant OTU, with $15.5 \%$ relative abundance (OTU 1), was classified as Campylobacter hyointestinalis; it had $96.9 \%$ sequence similarity to the best Greengenes type strain hit (Figure 1). The next most abundant (OTU 2; 7.8\% relative abundance) was classified as Kingella oralis, with $93.3 \%$ sequence similarity to the best Greengenes type strain hit. Then, OTU
$4,3,5$, and 6 were classified as Olivibacter sitiensis, Brachymonas denitrificans, Desulfobulbus rhabdoformis, and Azoarcus sp. (4.3\%, 4.2\%, 2.4\%, and $1.9 \%$ relative abundance, respectively; Figure 1). We found no significant differences in overall BEBM structure between the OTU abundances of RES and NRES cows or at the community level $(P=0.478)$; therefore, further data regarding BEBM structure for RES and NRES cows were analyzed together.

\section{Dynamic Shifts in the BEBM-Putative Indicator Phylotypes for SARA Challenge}

Species richness, diversity indices and evenness estimators differed significantly from baseline to adaptation and further during the SARA challenge (Table 4). The number of observed species, as well as the estimated species richness calculated by Chao estimator, remained constant from baseline to adaptation and decreased significantly during the SARA challenge. The abundance-based coverage estimator and Simpson diversity increased significantly from baseline to adaptation and decreased significantly from the adaptation period to the SARA challenge. The Shannon diversity index differed significantly among the 3 rumen conditions, with the highest estimated diversity at adaptation. The Shannon index-based measure of evenness revealed the highest evenness at the adaptation period. We found no significant differences in species richness or diversity

Table 1. Ruminal pH responses and concentrate and forage intake at the day before each sampling for responder (RES) and non-responder (NRES) $\operatorname{cows}^{1}$

\begin{tabular}{lcccc}
\hline Item $^{2}$ & RES & NRES & SEM & $P$-value \\
\hline Baseline & & & & \\
Daily mean pH & 6.40 & 6.44 & 0.01 & 0.82 \\
pH below 5.8 (min/d) & 0 & 0 & 0 & - \\
Minimum pH & 6.13 & 6.19 & 0.03 & 0.27 \\
Maximum pH & 6.66 & 6.65 & 0.03 & 0.84 \\
Concentrate intake (kg of DM/d) & 0 & 0 & 0 & - \\
Forage intake (kg of DM/d) & 8.63 & 9.05 & 0.46 & 0.68 \\
Adaptation & & & & \\
Daily mean pH & 5.92 & 6.22 & 0.09 & 0.11 \\
pH below 5.8 (min/d) & 495 & 135 & 132 & 0.21 \\
Minimum pH & 5.28 & 5.74 & 0.14 & 0.09 \\
Maximum pH & 6.41 & 6.61 & 0.07 & 0.18 \\
Concentrate intake (kg of DM/d) & 8.65 & 6.42 & 0.75 & 0.16 \\
Forage intake (kg of DM/d) & 7.05 & 6.71 & 0.80 & 0.85 \\
SARA & & & & \\
Daily mean pH & 5.80 & 6.38 & 0.12 & 0.01 \\
pH below 5.8 (min/d) & 653 & 30 & 139 & 0.03 \\
Minimum pH & 5.19 & 5.70 & 0.11 & 0.01 \\
Maximum pH & 6.34 & 6.89 & 0.12 & 0.02 \\
Concentrate intake (kg of DM/d) & 9.10 & 10.80 & 0.74 & 0.28 \\
Forage intake (kg of DM/d) & 5.48 & 6.66 & 0.59 & 0.36 \\
\hline LES cows that devis
\end{tabular}

${ }^{1} \mathrm{RES}=$ cows that developed SARA (ruminal $\mathrm{pH}$ below 5.8 for at least $330 \mathrm{~min} / \mathrm{d}$ ); NRES = cows that did not develop SARA according to the criteria defined above.

${ }^{2}$ Baseline was 2 wk of forage feeding, adaptation was 1 wk of adaptation to SARA diet, and the SARA challenge was 4 wk of the SARA diet. 
Table 2. Relative abundances of phyla of epimural bacteria in cows during baseline, adaptation, and the SARA challenge ${ }^{1}$

\begin{tabular}{|c|c|c|c|c|c|c|}
\hline Phylum & Relative abundance (\%) & \multicolumn{3}{|c|}{ Mean relative abundance (\%) } & SEM & $P$-value \\
\hline Proteobacteria & 45.19 & $52.83^{\mathrm{a}}$ & $40.76^{\mathrm{b}}$ & $41.75^{\mathrm{b}}$ & 3.33 & 0.009 \\
\hline Bacteroidetes & 15.85 & $10.37^{\mathrm{b}}$ & $14.10^{\mathrm{b}}$ & $22.64^{\mathrm{a}}$ & 2.21 & $<0.001$ \\
\hline Synergistetes & 1.70 & $1.44^{\mathrm{B}}$ & $1.77^{\mathrm{AB}}$ & $1.88^{\mathrm{A}}$ & 0.30 & 0.098 \\
\hline Elusimicrobia & 1.16 & 1.36 & 0.92 & 1.18 & 0.43 & 0.604 \\
\hline Lentisphaerae & 0.19 & $0.46^{\mathrm{a}}$ & $0.09^{\mathrm{b}}$ & $0.03^{\mathrm{b}}$ & 0.06 & $<0.001$ \\
\hline Plantomycetes & 0.15 & 0.19 & 0.12 & 0.13 & 0.05 & 0.382 \\
\hline Verrucomicrobia & 0.09 & $0.14^{\mathrm{a}}$ & $0.10^{\mathrm{ab}}$ & $0.04^{\mathrm{b}}$ & 0.02 & 0.005 \\
\hline Tenericutes & 0.09 & $0.10^{\mathrm{a}}$ & $0.12^{\mathrm{a}}$ & $0.08^{\mathrm{b}}$ & 0.02 & 0.003 \\
\hline Chloroflexi & 0.07 & $0.07^{\mathrm{ab}}$ & $0.09^{\mathrm{a}}$ & $0.05^{\mathrm{b}}$ & 0.01 & 0.042 \\
\hline Deferribacteres & 0.03 & $0.04^{\mathrm{A}}$ & $0.02^{\mathrm{AB}}$ & $0.01^{\mathrm{B}}$ & 0.01 & 0.087 \\
\hline
\end{tabular}

$\overline{\mathrm{a}, \mathrm{b}, \mathrm{A}, \mathrm{B}}$ Significant differences between rumen conditions in rows are indicated with different lowercase letters $(P \leq 0.05)$, and trends are indicated with uppercase letters $(P \leq 0.10)$.

${ }^{1}$ Baseline was 2 wk of forage feeding, adaptation was 1 wk of adaptation to the SARA diet, and the SARA challenge was 4 wk of the SARA diet.

between the RES and the NRES cows (Supplemental Table S3; https://doi.org/10.3168/jds.2016-11620). At the community level, calculated using the Bray-Curtis dissimilarity algorithm, samples taken at the baseline were more similar to each other than when compared with the adaptation and the SARA challenge, except for 1 cow (Figure 2A). Linear discriminant analysis revealed distinct clustering for the epimural microbiome in all 3 rumen conditions (Figure 2B).

Of 18 phyla, 12 showed significant shifts during our feeding experiment. Proteobacteria decreased significantly from the baseline to the adaptation, but remained constant from the adaptation to the SARA challenge, whereas Firmicutes increased from the baseline to the adaptation but decreased again during the SARA challenge. Bacteroidetes remained constant during the baseline and the adaptation, but increased during the SARA challenge. Spirochaetes, TM7, Lentisphaerae, and 2 other phyla decreased significantly from the baseline to the adaptation and Verrucomicrobia, Tenericutes, and Chloroflexi decreased significantly from the adaptation to the SARA challenge. Details of the statistical analysis at the phylum level are shown in Table 2.

Of the 50 most abundant genera, 24 showed significant shifts during the feeding experiment. Seven decreased significantly from the baseline to the adaptation (e.g., Campylobacter, Kingella, and Azospira) and 7 increased significantly from the baseline to the adaptation (e.g., Ruminococcus, Succinivibrio, and Lutispora), whereas 9 decreased significantly from the adaptation to the
SARA challenge (e.g., Lutispora, Pseudosphingobacterium, and Ornithobacterium) and 1 increased significantly from the adaptation to the SARA challenge (Butyrivibrio). Details of the statistical analysis of the 50 most abundant genera (greater than $0.25 \%$ relative abundance) are shown in Table 3.

At the OTU level, 24 of the 50 most abundant OTU showed significant shifts during the feeding experiment. In total, 7 decreased significantly from the baseline to the adaptation (e.g., Campylobacter-OTU 1, KingellaOTU 2, and Azoarcus-OTU 6), 6 increased from the baseline to the adaptation (e.g., Catabacter-OTU 18, Ruminobacter-OTU 23, and Succiniclasticum-OTU 25), 7 decreased from the adaptation to the SARA challenge (e.g., Catabacter-OTU 18, Ruminobacter-OTU 23, and Olivibacter-OTU 24), and 5 increased from the adaptation to the SARA challenge (e.g., Olivibacter-OTU 4, Alistipes-OTU 35, and Ruminobacter-OTU 41). Details of the statistical analysis at the OTU level are shown in Table S4 (https://doi.org/10.3168/jds.2016-11620).

\section{Correlation Analysis Between Mean Ruminal pH and OTU Abundances}

As shown in Figure 3A, we performed correlation analysis between ruminal $\mathrm{pH}$ and OTU abundances for all 8 cows (RES and NRES as 1 group), and 432 OTU showed significant correlations with mean ruminal $\mathrm{pH}$ over all 3 rumen conditions (i.e., baseline, adaptation, and the SARA challenge): 244 correlations were positive and 188 were negative. For better resolution, 
Figure 3B also displays the significant correlations of the 100 most abundant OTU; 10 showed positive correlations with mean ruminal $\mathrm{pH}$ (e.g., Kingella-OTU 2, Altererythrobacter-OTU 34, and Suttonella-OTU 14), and 12 showed negative correlations (e.g., SelenomonasOTU 92, Pontibacter-OTU 8, and Pontibacter-OTU
19; $P \leq 0.05$ ). To point out differences between RES and NRES, we also evaluated the correlations between ruminal $\mathrm{pH}$ and OTU for the data when divided between groups and found 197 positive and 97 negative correlations for RES cows (Supplemental Figures S1A and B; https://doi.org/10.3168/jds.2016-11620). Tak-

Table 3. Relative abundance of the 50 most abundant genera (those with more than $0.25 \%$ relative abundance) of epimural bacteria in cows during baseline, adaptation, and the 4-wk SARA challenge

\begin{tabular}{|c|c|c|c|c|c|}
\hline \multirow[b]{2}{*}{ Genus } & \multicolumn{3}{|c|}{ Mean relative abundance $(\%)$} & \multirow[b]{2}{*}{ SEM } & \multirow[b]{2}{*}{$P$-value } \\
\hline & Baseline & Adaptation & SARA & & \\
\hline Campylobacter & $20.05^{\mathrm{a}}$ & $11.15^{\mathrm{b}}$ & $15.15^{\mathrm{ab}}$ & 2.16 & 0.002 \\
\hline Kingella & $12.46^{\mathrm{a}}$ & $3.57^{\mathrm{b}}$ & $7.31^{\mathrm{b}}$ & 1.28 & $<0.001$ \\
\hline Desulfobulbus & 6.55 & 6.56 & 7.12 & 1.00 & 0.841 \\
\hline Brachymonas & 5.00 & 4.37 & 3.16 & 0.79 & 0.121 \\
\hline Acidaminobacter & 4.52 & 4.01 & 2.51 & 0.90 & 0.258 \\
\hline Alkalibaculum & $4.06^{\mathrm{AB}}$ & $4.25^{\mathrm{A}}$ & $2.02^{\mathrm{B}}$ & 1.02 & 0.066 \\
\hline Ruminococcus & $1.94^{\mathrm{b}}$ & $4.48^{\mathrm{a}}$ & $3.57^{\mathrm{ab}}$ & 1.75 & 0.186 \\
\hline Succinivibrio & $0.08^{\mathrm{b}}$ & $6.97^{\mathrm{a}}$ & $1.56^{\mathrm{ab}}$ & 1.91 & 0.027 \\
\hline Oscillibacter & 2.75 & 2.84 & 2.59 & 0.31 & 0.764 \\
\hline Anaerophaga & $1.02^{\mathrm{b}}$ & $2.24^{\mathrm{ab}}$ & $3.72^{\mathrm{a}}$ & 0.68 & 0.020 \\
\hline Saccharofermentans & $2.40^{\mathrm{A}}$ & $2.33^{\mathrm{AB}}$ & $1.62^{\mathrm{B}}$ & 0.26 & 0.053 \\
\hline Lutispora & $1.61^{\mathrm{b}}$ & $2.92^{\mathrm{a}}$ & $1.37^{\mathrm{b}}$ & 0.45 & 0.003 \\
\hline Azospira & $3.39^{\mathrm{a}}$ & $0.89^{\mathrm{b}}$ & $1.40^{\mathrm{b}}$ & 0.41 & $<0.001$ \\
\hline Pseudosphingobacterium & $1.94^{\mathrm{a}}$ & $2.96^{\mathrm{a}}$ & $0.48^{\mathrm{b}}$ & 0.28 & $<0.001$ \\
\hline Flavonifractor & $1.27^{\mathrm{B}}$ & $2.02^{\mathrm{A}}$ & $1.94^{\mathrm{AB}}$ & 0.59 & 0.075 \\
\hline Ruminobacter & $0.12^{\mathrm{b}}$ & $3.04^{\mathrm{a}}$ & $1.80^{\mathrm{ab}}$ & 1.12 & 0.007 \\
\hline Acetivibrio & 1.67 & 1.98 & 1.24 & 0.40 & 0.391 \\
\hline Desulfovibrio & $2.02^{\mathrm{A}}$ & $1.03^{\mathrm{B}}$ & $1.44^{\mathrm{AB}}$ & 0.38 & 0.074 \\
\hline Elusimicrobium & 1.36 & 0.92 & 1.18 & 0.43 & 0.604 \\
\hline Rikenella & $0.73^{\mathrm{b}}$ & $1.46^{\mathrm{a}}$ & $1.29^{\mathrm{ab}}$ & 0.26 & 0.022 \\
\hline Succiniclasticum & $0.53^{\mathrm{B}}$ & $1.09^{\mathrm{AB}}$ & $1.38^{\mathrm{A}}$ & 0.26 & 0.066 \\
\hline Fastidiospila & $0.67^{\mathrm{B}}$ & $1.06^{\mathrm{A}}$ & $1.10^{\mathrm{A}}$ & 0.19 & 0.065 \\
\hline Sporobacter & 0.72 & 0.79 & 1.06 & 0.68 & 0.384 \\
\hline Ornithobacterium & $0.87^{\mathrm{ab}}$ & $1.13^{\mathrm{a}}$ & $0.54^{\mathrm{b}}$ & 0.14 & 0.006 \\
\hline Anaerovibrio & 0.82 & 0.94 & 0.72 & 0.14 & 0.694 \\
\hline Suttonella & 0.91 & 0.37 & 1.16 & 0.43 & 0.204 \\
\hline Papillibacter & 0.62 & 0.77 & 0.72 & 0.17 & 0.769 \\
\hline Aminobacterium & 0.60 & 0.65 & 0.82 & 0.17 & 0.245 \\
\hline Coprobacillus & $0.90^{\mathrm{a}}$ & $0.67^{\mathrm{b}}$ & $0.44^{\mathrm{c}}$ & 0.07 & $<0.001$ \\
\hline Dongia & $0.56^{\mathrm{AB}}$ & $0.54^{\mathrm{B}}$ & $0.83^{\mathrm{A}}$ & 0.17 & 0.060 \\
\hline Pseudoflavonifractor & 0.40 & 0.69 & 0.76 & 0.14 & 0.141 \\
\hline Tannerella & 0.43 & 0.75 & 0.54 & 0.18 & 0.295 \\
\hline Selenomonas & $0.06^{\mathrm{b}}$ & $0.40^{\mathrm{ab}}$ & $1.20^{\mathrm{a}}$ & 0.29 & 0.019 \\
\hline Thioreductor & $1.16^{\mathrm{a}}$ & $0.36^{\mathrm{b}}$ & $0.15^{\mathrm{b}}$ & 0.12 & $<0.001$ \\
\hline Clostridium_XlVb & $0.42^{\mathrm{b}}$ & $0.75^{\mathrm{a}}$ & $0.45^{\mathrm{b}}$ & 0.08 & 0.007 \\
\hline Cellulosilyticum & $0.55^{\mathrm{ab}}$ & $0.81^{\mathrm{a}}$ & $0.26^{\mathrm{b}}$ & 0.19 & 0.041 \\
\hline Kiloniella & 0.15 & 0.67 & 0.70 & 0.31 & 0.325 \\
\hline Clostridium_IV & $0.23^{\mathrm{b}}$ & $1.06^{\mathrm{a}}$ & $0.17^{\mathrm{b}}$ & 0.12 & $<0.001$ \\
\hline Pyramidobacter & 0.30 & 0.53 & 0.51 & 0.10 & 0.129 \\
\hline Gracilibacter & $0.21^{\mathrm{B}}$ & $0.77^{\mathrm{A}}$ & $0.35^{\mathrm{AB}}$ & 0.18 & 0.072 \\
\hline Bifidobacterium & 0.00 & 1.14 & 0.21 & 0.61 & 0.346 \\
\hline Brevinema & $0.93^{\mathrm{a}}$ & $0.21^{\mathrm{b}}$ & $0.13^{\mathrm{b}}$ & 0.10 & $<0.001$ \\
\hline Dehalobacter & 0.31 & 0.41 & 0.51 & 0.11 & 0.426 \\
\hline Anaerorhabdus & $0.51^{\mathrm{a}}$ & $0.45^{\mathrm{a}}$ & $0.22^{\mathrm{b}}$ & 0.07 & 0.001 \\
\hline Syntrophococcus & $0.52^{\mathrm{a}}$ & $0.35^{\mathrm{ab}}$ & $0.25^{\mathrm{b}}$ & 0.05 & 0.001 \\
\hline Holdemania & 0.33 & 0.34 & 0.32 & 0.10 & 0.984 \\
\hline Petrimonas & $0.39^{\mathrm{a}}$ & $0.42^{\mathrm{a}}$ & $0.13^{\mathrm{b}}$ & 0.09 & $<0.001$ \\
\hline Butyrivibrio & $0.26^{\mathrm{ab}}$ & $0.22^{\mathrm{b}}$ & $0.41^{\mathrm{a}}$ & 0.06 & 0.042 \\
\hline Bilophila & 0.35 & 0.24 & 0.26 & 0.06 & 0.223 \\
\hline Thermovirga & $0.35^{\mathrm{A}}$ & $0.35^{\mathrm{A}}$ & $0.11^{\mathrm{B}}$ & 0.10 & 0.067 \\
\hline
\end{tabular}




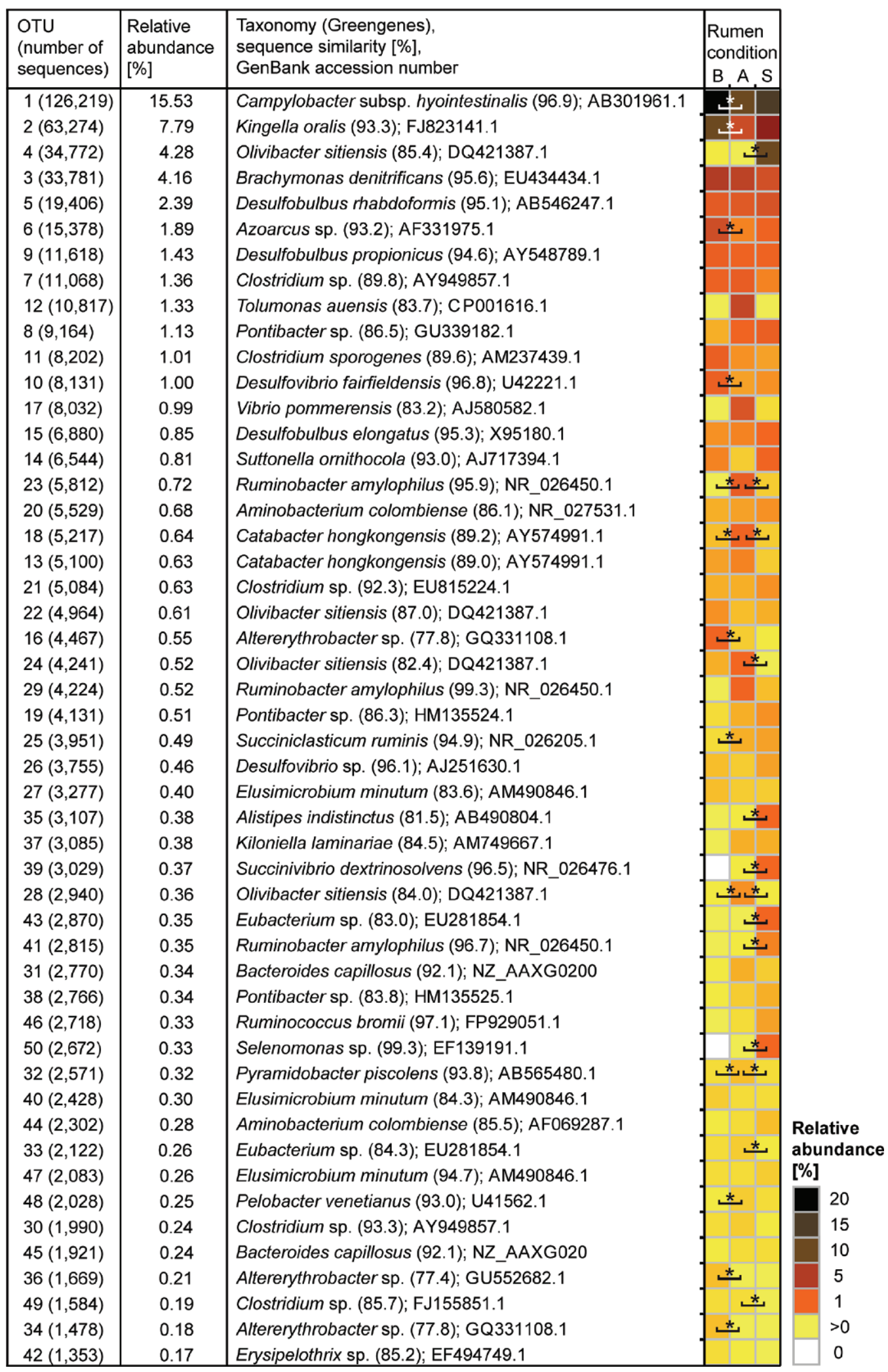

Figure 1. Heatmap showing the 50 most abundant operational taxonomic units (OTU) with relative abundance and best Greengenes type strain hit. Statistically significant shifts are marked with an asterisk. Rumen conditions are as follows: baseline (B) was 2 wk of forage feeding, adaptation (A) was 1 wk of adaptation to the SARA diet, and the SARA challenge (S) was 4 wk of the SARA diet. Taxonomic classifications should be considered with care due to the low sequence similarity of some OTU to the best type strain hit. Color version available online. 


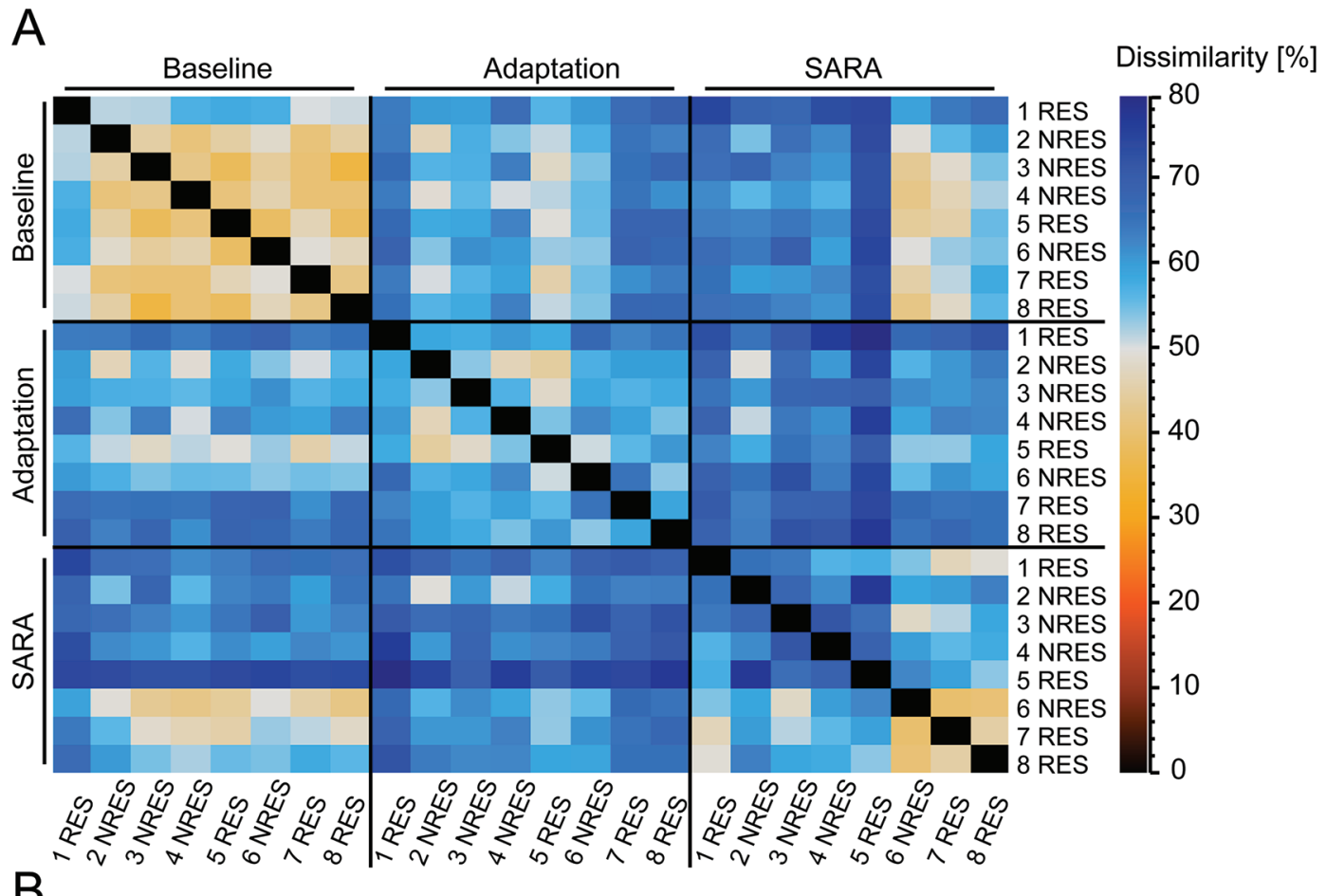

$\mathrm{B}$

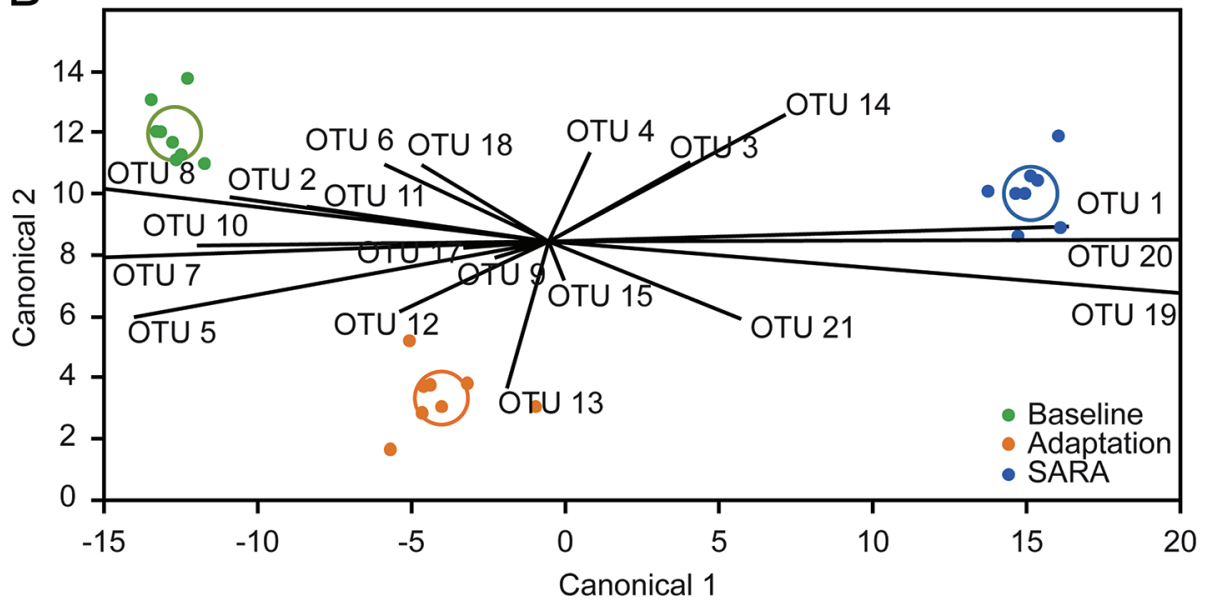

Figure 2. Beta diversity displayed as (A) a heatmap showing Bray-Curtis dissimilarity among bacterial epimural communities [cow numbers and affiliation to responder (RES) and nonresponder (NRES) groups are indicated]; (B) linear discriminant analysis with operational taxonomic units (OTU) detected in every rumen condition, displayed as a canonical diagram $(\mathrm{n}=1,882$; method $=$ Ward $)$. Baseline was 2 wk of forage feeding, adaptation was $1 \mathrm{wk}$ of adaptation to the SARA diet, and the SARA challenge was $4 \mathrm{wk}$ of the SARA diet. Color version available online.

Table 4. Dynamics of species richness and diversity indices of epimural bacteria during baseline, adaptation, and the 4-wk SARA challenge ${ }^{1}$

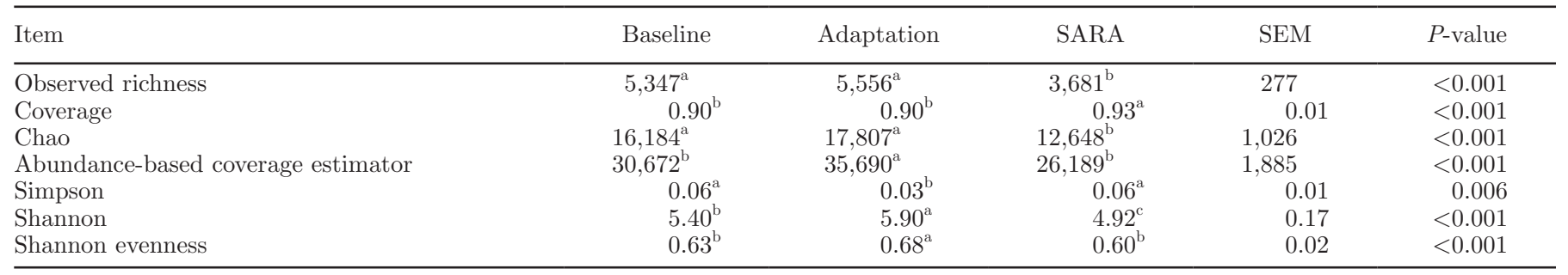

\footnotetext{
${ }^{a-c}$ Significant differences between rumen conditions in rows are indicated with different lowercase letters $(P \leq 0.05)$.

${ }^{1}$ Baseline was $2 \mathrm{wk}$ of forage feeding, adaptation was $1 \mathrm{wk}$ of adaptation to the SARA diet, and the SARA challenge was 4 wk of the SARA diet.
} 
A

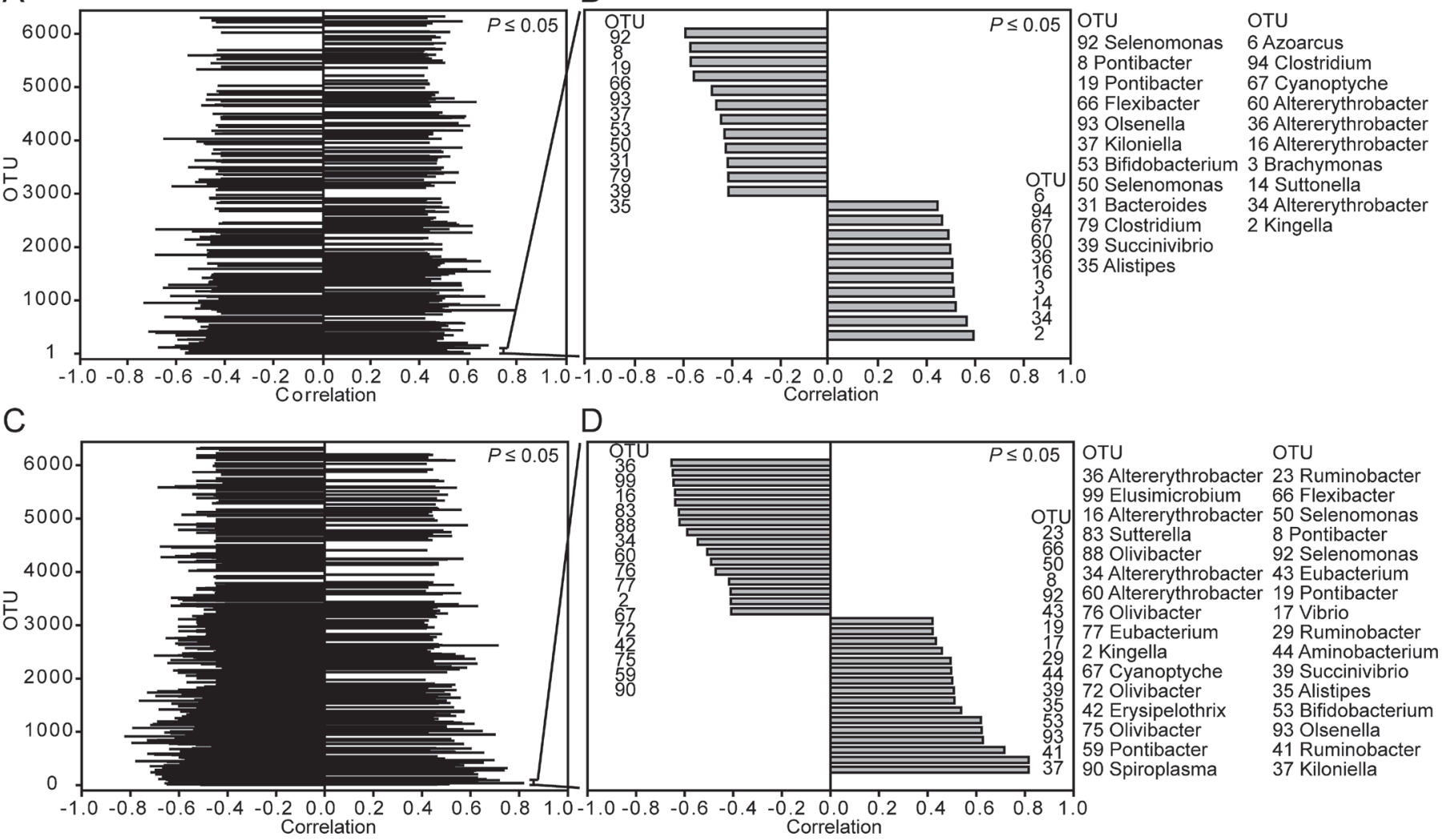

Figure 3. (A) Correlation analysis between mean ruminal $\mathrm{pH}$ and operational taxonomic units (OTU) over all 3 rumen conditions and responses of $\mathrm{pH}$ during the SARA challenge; all significant $(P \leq 0.05)$ correlations are shown; (B) only significant correlations of the 100 most abundant OTU with ruminal pH are shown. (C) Correlation analysis between average grain intake and OTU over all 3 rumen conditions; all significant $(P \leq 0.05)$ correlations are shown; (D) only significant correlations of the 100 most abundant OTU with grain intake are shown.

ing a closer look at the 100 most abundant OTU, we found 12 positive (e.g., Altererythrobacter-OTU 16, Altererythrobacter-OTU 34, and AltererythrobacterOTU 36) and 5 negative (e.g., Succiniclasticum-OTU 25, Bacteroides-OTU 31, and Olivibacter-OTU 4) correlations. The NRES cows showed 399 negative correlations and no positive correlations. Of the 399 negative correlations, only 1 was among the 100 most abundant OTU (Ruminobacter-OTU 23; Supplemental Figures S1A and B).

\section{Correlations Between Concentrate Intake and OTU Abundances}

As shown in Figure 3C, we performed correlation analysis for all 8 cows (RES and NRES as 1 group), and 743 OTU had significant correlations with average grain intake over all 3 rumen conditions: 210 correlations were positive and 533 were negative. For better resolution, Figure 3D also displays the significant correlations of the 100 most abundant OTU; 16
OTU correlated positively with average grain intake (e.g., Kiloniella-OTU 37, Ruminobacter-OTU 41, and Olsenella-OTU 93) and 16 correlated negatively with average grain intake (e.g., Altererythrobacter-OTU 36, Elusimicrobium-OTU 99, and Altererythrobacter-OTU $16 ; P \leq 0.05)$. To point out differences between RES and NRES, we then calculated the correlations for the 2 groups separately (Supplemental Figures S1C and D; https://doi.org/10.3168/jds.2016-11620). Here, we found 15 positive and 313 negative correlations for the RES, including 3 positive (Flexibacter-OTU 66, Olivibacter-OTU 28 and Aminobacterium-OTU 44) and 9 negative (e.g., Altererythrobacter-OTU 34, Altererythrobacter-OTU 16 and Kingella-OTU 2) correlations within the 100 most abundant OTU. We also found 65 positive and 148 negative correlations for the NRES, including 2 positive (Kiloniella-OTU 37 and Ruminobacter-OTU 41) and 10 negative (e.g., Altererythrobacter-OTU 36, Altererythrobacter-OTU 16, and Altererythrobacter-OTU 60) correlations within the 100 most abundant OTU (Supplemental Figure S1C and 
D). Taxonomic classifications of OTU 51 to 100 are shown in Supplemental Table S5.

\section{Confirmation of Sequencing Data by $q P C R$}

We confirmed the high abundance of the 10 most abundant OTU using qPCR (Figure 4). The gene copy numbers per gram of biopsy material were between $10^{6}$ and $10^{11}$. Five of the 12 most abundant OTU $(\geq 1 \%$ relative abundance) showed significant shifts between rumen conditions, and overall trends were confirmed by $\mathrm{qPCR}$, although some significant abundance shifts found in the sequencing data were not confirmed by the qPCR data. Nevertheless, numerical trends supported the findings from the sequencing data (Figure 4).

\section{DISCUSSION}

This study aimed at determining the extent to which the BEBM community structure is affected during adaptation from a forage-based to a concentrate-rich diet and after 4 wk of continuous concentrate-based feeding. Our data suggested that strict forage feeding during the baseline period allowed the BEBM to adjust to overall physiological rumen conditions (i.e., constant $\mathrm{pH}$ of 6.2-6.7). Indeed, the high similarity within samples taken at baseline indicated that the BEBM of cows was equally adapted, stable, and comparable among cows. During this period, the constant availability of digestible fiber fractions, non-protein $\mathrm{N}$, and fermentable protein fractions of the mainly grass silage diet
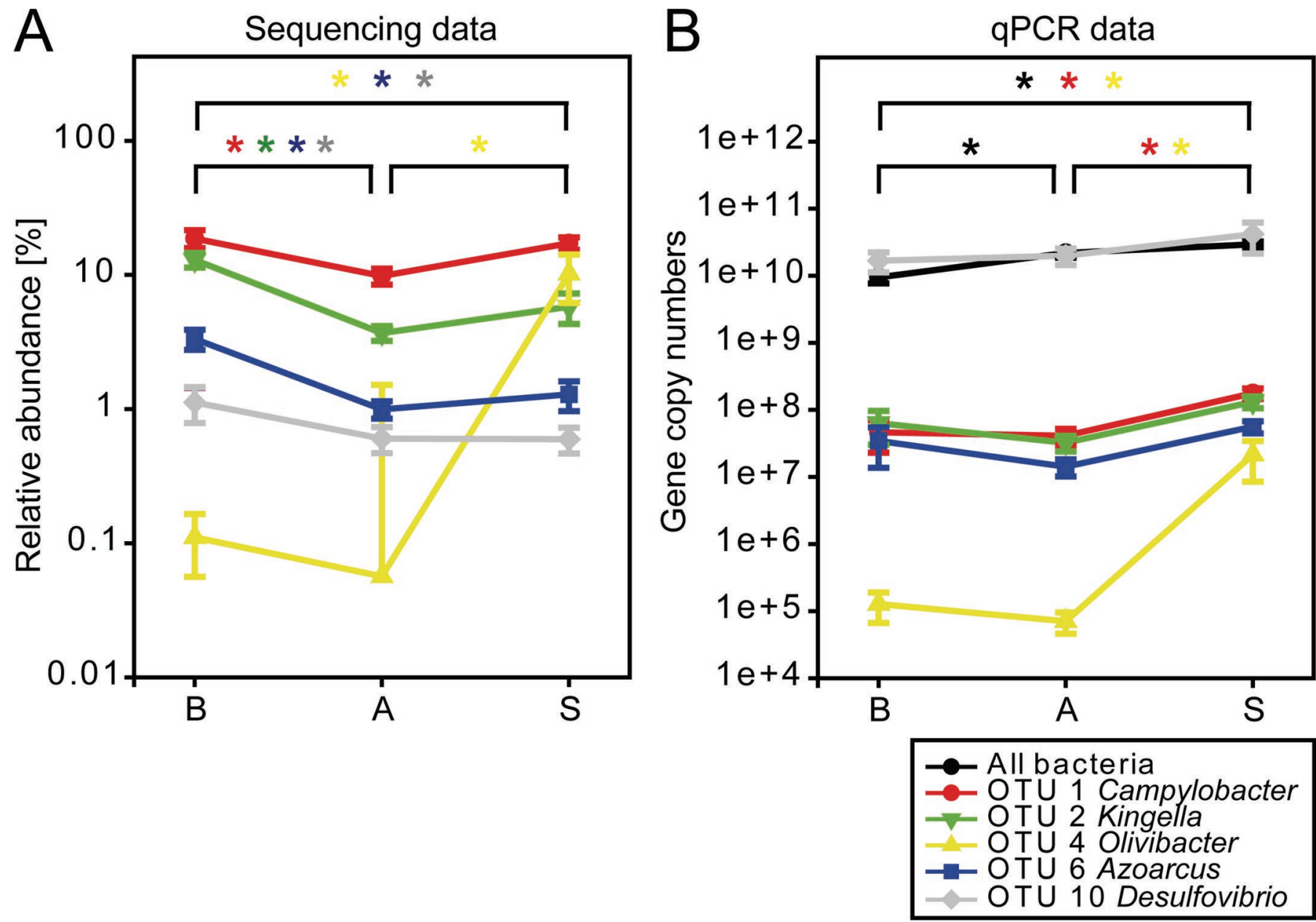

Figure 4. Comparison between sequencing data and quantitative PCR data. (A) Sequencing data of highly abundant operational taxonomic units (OTU) with significant differences in relative abundance between baseline, adaptation, and the SARA challenge; (B) quantitative PCR data for all bacteria and OTU. Significant differences among rumen conditions are indicated by an asterisk in the respective shade (color) of the OTU in the top of panels A and B. Rumen conditions are depicted on the x-axis: baseline was 2 wk of forage feeding (B), adaptation was 1 wk of adaptation to the SARA diet (A), and the SARA challenge was 4 wk of the SARA diet (S). Taxonomic classifications should be considered with care due to the low sequence similarity of some OTU to the best type strain hit. Color version available online. 
dominated the substrate availability, and cereal starch was largely lacking.

Differences in ruminal $\mathrm{pH}$ drop between cows during a continuous concentrate-rich challenge is a finding that has been reported earlier (Penner et al., 2007; Mohammed et al., 2012; Schlau et al., 2012). However, this study is one of the first to demonstrate, using a high-throughput sequencing approach, that the BEBM community structure in cows is less responsive to strong ruminal $\mathrm{pH}$ drops. Individual cows might employ methods of ruminal $\mathrm{pH}$ control that vary in their effectiveness. Ruminal pH is affected by the amount of fermentable substrate intake, which was similar between the RES and NRES cows (Aschenbach et al., 2011). In line with previous results (Humer et al., 2015), we found no difference in DMI between RES and NRES, indicating that substrate availability was not the reason for the different responses in ruminal $\mathrm{pH}$. The RES and NRES could have differed in chewing activity, absorption processes of SCFA across the rumen epithelium (which are instrumental for the neutralization of protons in the ruminal lumen), and further regulation of ruminal $\mathrm{pH}$ (Zebeli et al., 2008; Aschenbach et al., 2011). It has been assumed that the majority of neutralization of free protons is done by the rumen epithelium (e.g., by $\mathrm{SCFA}^{-} / \mathrm{HCO}_{3}{ }^{-}$exchange), and the respective absorptive surface can be directly affected by ruminal SCFA concentration (Aschenbach et al., 2011; Penner et al., 2011). However, to date we can only speculate about which mechanisms are responsible for the varying ruminal $\mathrm{pH}$ responses among animals to a diet-induced SARA challenge, because none of the neutralization processes was measured in the present study.

Ruminal $\mathrm{pH}$ is also known to play a key role in the regulation of microbial homeostasis in the rumen, and fiber-degrading bacteria are especially sensitive to strong changes in ruminal $\mathrm{pH}$ (Russell and Wilson, 1996; Jouany, 2006), so the lack of clear effects on the BEBM structure of a drop in $\mathrm{pH}$ during the SARA challenge was unexpected. The full magnitude of the drop in ruminal $\mathrm{pH}$ might be more visible in shifts in the microbiome of the rumen content than in the $\mathrm{BEBM}$, because the ruminal $\mathrm{pH}$ represents the luminal ventral reticulorumen (Duffield et al., 2004; Klevenhusen et al., 2014) rather than the $\mathrm{pH}$ around the BEBM. A lack of response in the BEBM during the SARA challenge can also be explained by the presence of buffer substances at the interface of the rumen epithelium and BEBM. For example, urea and bicarbonate flow into the rumen lumen across the rumen epithelium (Abdoun et al., 2006). These 2 buffering substances might neutralize protons and increase the $\mathrm{pH}$ at the BEBM attachment sites in rumen epithelium (Cheng and Wallace, 1979; Leonhard-Marek et al., 2006), which could lead to the promotion of $\mathrm{pH}$-sensitive members of the BEBM community. In addition, differences in the community structure and sensitivity to $\mathrm{pH}$ drops between the BEBM and the microbial community in the rumen content have been previously reported (Mao et al., 2015; Liu et al., 2016), with Proteobacteria being significantly more abundant in the BEBM at the phylum level, and a higher abundance of the genera Campylobacter and Desulfobulbus. The latter phylotypes were highly abundant in our study and are not known to be especially acid-sensitive (Lien et al., 1998; Murphy et al., 2003). This fact and the assumption of a relatively stable $\mathrm{pH}$ at the epithelium sites likely explain the stronger correlation between concentrate intake and OTU in the BEBM than between ruminal $\mathrm{pH}$ and the same OTU. Indeed, our data suggest that the amount of substrate ingested affected the BEBM composition more strongly than the ruminal $\mathrm{pH}$ per se, although few OTU correlated negatively with ruminal $\mathrm{pH}$ and positively with concentrate intake. However, the fact that more OTU correlated with concentrate intake than with ruminal $\mathrm{pH}$ indicated that the effect of substrate intake is a step ahead of the effect of ruminal $\mathrm{pH}$. This is understandable, because although concentrate intake affects ruminal $\mathrm{pH}$, the latter is also regulated by neutralization processes, which are less dependent on concentrate intake (Aschenbach et al., 2011). In addition, the amount and the type of substrate are highly important for the growth of rumen microbes, including the BEBM, whereas ruminal $\mathrm{pH}$ might not be as important for certain bacteria in the BEBM. It is well known that the growth and activity (and therefore homeostatic regulation) of rumen microbes depend mainly on substrate availability and specific microbe preferences for substrates (Henderson et al., 2015), although a certain host specificity has been observed (Li et al., 2009; Weimer et al., 2010; Weimer, 2015). Nevertheless, the regulation and substrate preferences of the BEBM are poorly understood and it is unknown which metabolites trigger abundance shifts at the BEBM. Higher amounts of easily fermentable carbohydrates in the SARA diet or increased protein content (and the respective metabolites), both at the expense of NDF, might be at least partially responsible for shifts in community composition.

Compared with luminal rumen microbes, epimural microbes are believed to be more involved in protein metabolism, epithelium proliferation, and diseases (Mao et al., 2015), or in SCFA absorption through the rumen wall by modulating the expression of genes responsible for the absorptive processes in the rumen epithelium (Chen et al., 2012) than in carbohydrate fermentation. Therefore, the shifts in the BEBM, as well as different responses in ruminal $\mathrm{pH}$ to a high-concentrate diet in 
our study, might be different than in studies where the bacterial community of the rumen content was examined. In line with our study, Chen et al. (2012) found no significant differences in the species richness of the epimural bacterial community of cows that responded to an acidotic challenge or not. However, the PCR-DGGE profiles of the responder and non-responder cows showed a clear separation, in contrast to our study. The reason for the discrepancy might be the lower forage-to-concentrate ratio used in Chen et al. (2012) (85\% concentrate) and the longer duration of the feeding experiment (58 d). Furthermore, in our study, we characterized the establishment of SARA according to the time span of ruminal $\mathrm{pH}$ below 5.8 during the day before rumen papillae sampling (Zebeli et al., 2008) at adaptation and the SARA challenge. In contrast, Chen et al. (2012) classified SARA according to an acidosis index calculated by dividing the area of ruminal $\mathrm{pH}$ below 5.8 by DMI. Nevertheless, as described in our companion study (Pourazad et al., 2016), all cows experienced SARA during the experiment, albeit with day-to-day variations, and this might explain why the epimural bacterial community structure did not cluster according to response to the SARA challenge.

Our findings for the changes in diversity and phyla abundance observed during the SARA challenge, independent of RES and NRES grouping, indicate that the magnitude of ruminal $\mathrm{pH}$ decrease during the SARA challenge is not of critical importance for the composition of the BEBM community. Instead, the increased availability of easily fermentable substrate for $4 \mathrm{wk}$ elicited changes in the BEBM compared with the baseline and the adaptation, when no concentrates (baseline) or increasing amounts of concentrates (adaptation) gradually replaced forages in the diet. Usually, with higher amounts of easily degradable carbohydrates, the ratio of Firmicutes to Bacteroidetes increases, because Firmicutes generally benefit from easily digestible carbohydrates (Kallus and Brandt, 2012), and many gramnegative Bacteroidetes are sensitive to $\mathrm{pH}$ (Kampmann et al., 2012). It has also been shown that the relative abundance of Firmicutes in the rumen increased with increasing amounts of concentrate fed (Wetzels et al., 2015; Sato, 2016). In the present study we also found that Firmicutes increased from the baseline to the adaptation, but decreased from the adaptation to the SARA challenge, whereas Bacteroidetes increased from the adaptation to the SARA challenge. The detailed mechanisms responsible for these shifts cannot yet be explained, but it is noticeable that abundance shifts in high-throughput sequencing data represent only relative abundance. Therefore, we cannot draw conclusions about absolute abundance shifts in the BEBM. Shifts in the BEBM do seem to occur in large part in less abundant phylotypes and not solely in highly abundant ones. For example, most Synergistetes degrade amino acids and do not use carbohydrates (Hugenholtz et al., 2009). We observed a trend of increasing Synergistetes when we compared the 4 -wk high-concentrate diet to the baseline diet. This might be explained by increasing amounts of protein in the diet from the baseline to the adaptation. Additionally, the shifts in diversity (increasing diversity from the baseline to the adaptation and decreasing diversity from the adaptation to the SARA challenge) seemed to be displayed mainly by less abundant phylotypes that thrive with better substrate availability during the adaptation and by others that vanished with constant high-concentrate feeding during the SARA challenge. Instead, highly abundant phylotypes showed only abundance changes but did not vanish. However, the high diversity of taxa belonging to highly abundant phyla (Proteobacteria, Firmicutes, and Bacteroidetes) makes it difficult to determine a response to substrate that applies for all taxa within a phylum.

For this reason, a response to diet should be described at a lower taxonomic level, such as OTU level. Because the sequence similarity to the best type strain hits of the most abundant OTU was mostly below $97 \%$, conclusions about metabolic function can rarely be drawn at the OTU level. As well, the lack of reference sequences in the public databases limits taxonomic resolution of high-throughput sequencing data sets. Below, we discuss some of the most abundant OTU and their putative effect with regards to the actual state of knowledge. The most abundant OTU in this study was classified as Campylobacter (OTU 1), which has been detected in high numbers in the BEBM before (Zhao and $\mathrm{Bu}, 2014$; Mao et al., 2015; Liu et al., 2016). Campylobacter does not ferment carbohydrates (Indikova et al., 2015), but some Campylobacter species might function as nitrate reducers in the rumen (Lin et al., 2013; Zhao et al., 2015). This finding is in line with our results: Campylobacter-OTU 1 decreased from the baseline to the adaptation, possibly caused by higher nitrate levels in the forages we used exclusively as the baseline diet. We found no abundance shift from the adaptation to the SARA challenge, indicating the adaptation to the constant nitrate amounts in the diet, and no significant correlation with ruminal $\mathrm{pH}$ or concentrate intake. The second most abundant OTU was classified as Kingella, which belongs to the Neisseriaceae family. This family has been detected in rumen samples before (Jiao et al., 2015; Wetzels et al., 2015, 2016). However, the significant decrease of Kingella-OTU 2 we observed from the baseline to the adaptation is in accordance with 3 recent studies, where related OTU decreased with increasing grain feeding in goats (Jiao 
et al., 2015; Wetzels et al., 2015) and cows (Wetzels et al., 2016). Additionally, Kingella-OTU 2 correlated positively with ruminal $\mathrm{pH}$ and negatively with concentrate intake, making it a putative indicator phylotype for high-forage feeding. Another highly abundant OTU, OTU 4, was classified as Olivibacter. Sequences classified as Olivibacter have been obtained from rumen samples in previous studies (Yin et al., 2014; Wetzels et al., 2016). At the OTU level, OTU 4 might be an indicator phylotype for long-term concentrate feeding, because its relative abundance increased significantly from adaptation to the SARA challenge, although it has not been found to correlate significantly with ruminal $\mathrm{pH}$ or concentrate intake. Olivibacter-OTU 72, 75, and 88 correlated negatively with concentrate intake, making them putative indicator phylotypes for highforage feeding. This confirms that taxonomic levels higher than OTU level might not be well suited for defining indicator phylotypes. Nevertheless, the function of these phylotypes (OTU 2, OTU 4, OTU 72, OTU 75 , and OTU 88) in the rumen also remains unclear, and the low sequence similarity to the best type strain hit does not allow for further speculation about metabolic function. Further experimental approaches will be needed to confirm putative indicator phylotypes.

The duration of the diet-induced SARA challenge in this study was $4 \mathrm{wk}$, with $1 \mathrm{wk}$ adaptation, and is considered to be long-term diet-induced SARA. Most of the previous studies in cows with diet-induced SARA are of shorter duration, such as 1-wk (Khafipour et al., 2011) or 1-d feed restriction followed by increased concentrate intake (McCann et al., 2016). We chose a SARA model that is closer to production conditions, with cows experiencing SARA during early lactation for weeks. However, we have no consistent definition of short-term or long-term SARA, and further research is necessary to establish a SARA model according to real-life conditions.

\section{CONCLUSIONS}

The results of our study revealed strong shifts in highly abundant members of the BEBM during a longterm continuous SARA feeding challenge. Diversity increased during a 1-wk gradual adaptation period to a high-grain diet and decreased again with a 4-wk continuous high-grain diet. Shifts in the BEBM during the SARA challenge were not $\mathrm{pH}$-dependent, indicating that the BEBM structure was resistant to a strong drop in $\mathrm{pH}$ during the SARA challenge. However, the BEBM was responsive to a 4 -wk $60 \%$ concentrate feeding, suggesting that the amount of substrate fed strongly influences BEBM structure. More research is needed to characterize the highly abundant members of the
BEBM and their function in the rumen, especially the significance of the observed changes in diversity in rumen health in early lactating dairy cows and finishing beef cattle that are fed concentrate-rich diets over long time periods.

\section{ACKNOWLEDGMENTS}

Funding for this study was provided by the project D-I.INFLACOW, LS12-010 of the Vienna Science and Technology Fund (WWTF). The authors acknowledge the excellent help of the staff of the research station Kremesberg at Vetmeduni Vienna during the animal experiment. The great support of F. Klevenhusen, A. Dockner, M. Wild, and M. Salzmann (Institute of Animal Nutrition and Functional Plant Compounds) during the animal experiment and S. Kuchling (Ages, Graz) during the data analysis is also highly appreciated.

\section{REFERENCES}

Abdoun, K., F. Stumpff, and H. Martens. 2006. Ammonia and urea transport across the rumen epithelium: A review. Anim. Health Res. Rev. 7:43-59. https://doi.org/10.1017/S1466252307001156.

Aschenbach, J. R., G. B. Penner, F. Stumpff, and G. Gabel. 2011. Ruminant nutrition symposium: Role of fermentation acid absorption in the regulation of ruminal pH. J. Anim. Sci. 89:1092-1107. https://doi.org/10.2527/jas.2010-3301.

Bates, D., M. Machler, B. M. Bolker, and S. C. Walker. 2015. Fitting linear mixed-effects models using lme4. J. Stat. Softw. 67:1-48. https://doi.org/10.18637/jss.v067.i01.

Boerman, J. P., S. B. Potts, M. J. VandeHaar, M. S. Allen, and A. L. Lock. 2015. Milk production responses to a change in dietary starch concentration vary by production level in dairy cattle. J. Dairy Sci. 98:4698-4706. https://doi.org/10.3168/jds.2014-8999.

Bustin, S. A., V. Benes, J. A. Garson, J. Hellemans, J. Huggett, M. Kubista, R. Mueller, T. Nolan, M. W. Pfaffl, G. L. Shipley, J. Vandesompele, and C. T. Wittwer. 2009. The MIQE guidelines: Minimum information for publication of quantitative realtime PCR experiments. Clin. Chem. 55:611-622. https://doi. org/10.1373/clinchem.2008.112797.

Caporaso, J. G., J. Kuczynski, J. Stombaugh, K. Bittinger, F. D. Bushman, E. K. Costello, N. Fierer, A. G. Pena, J. K. Goodrich, J. I. Gordon, G. A. Huttley, S. T. Kelley, D. Knights, J. E. Koenig, R. E. Ley, C. A. Lozupone, D. McDonald, B. D. Muegge, M. Pirrung, J. Reeder, J. R. Sevinsky, P. J. Turnbaugh, W. A. Walters, J. Widmann, T. Yatsunenko, J. Zaneveld, and R. Knight. 2010. QIIME allows analysis of high-throughput community sequencing data. Nat. Methods 7:335-336. https://doi.org/10.1038/ nmeth.f.303.

Chen, Y., M. Oba, and L. L. Guan. 2012. Variation of bacterial communities and expression of Toll-like receptor genes in the rumen of steers differing in susceptibility to subacute ruminal acidosis. Vet. Microbiol. 159:451-459. https://doi.org/10.1016/j. vetmic.2012.04.032.

Cheng, K. J., R. P. McCowan, and J. W. Costerton. 1979. Adherent epithelial bacteria in ruminants and their roles in digestive tract function. Am. J. Clin. Nutr. 32:139-148.

Cheng, K. J., and R. J. Wallace. 1979. The mechanism of passage of endogenous urea through the rumen wall and the role of ureolytic epithelial bacteria in the urea flux. Br. J. Nutr. 42:553-557.

DeSantis, T. Z., P. Hugenholtz, N. Larsen, M. Rojas, E. L. Brodie, K. Keller, T. Huber, D. Dalevi, P. Hu, and G. L. Andersen. 
2006. Greengenes, a chimera-checked $16 \mathrm{~S}$ rRNA gene database and workbench compatible with ARB. Appl. Environ. Microbiol. 72:5069-5072. https://doi.org/10.1128/AEM.03006-05.

Duffield, T., J. C. Plaizier, A. Fairfield, R. Bagg, G. Vessie, P. Dick, J. Wilson, J. Aramini, and B. McBride. 2004. Comparison of techniques for measurement of rumen $\mathrm{pH}$ in lactating dairy cows. J. Dairy Sci. 87:59-66. https://doi.org/10.3168/jds.S00220302(04)73142-2.

Fay, J. P., K. J. Cheng, and J. W. Costerton. 1979. Production of alkaline phosphatase by epithelial cells and adherent bacteria of the bovine rumen and abomasum. Can. J. Microbiol. 25:932-936.

Henderson, G., F. Cox, S. Ganesh, A. Jonker, and W. Young., Global Rumen Census Collaborators, andJanssen, P. H. 2015. Rumen microbial community composition varies with diet and host, but a core microbiome is found across a wide geographical range. Sci. Rep. 5:14567. https://doi.org/10.1038/srep14567.

Hook, S. E., M. A. Steele, K. S. Northwood, J. Dijkstra, J. France, A. D. Wright, and B. W. McBride. 2011. Impact of subacute ruminal acidosis (SARA) adaptation and recovery on the density and diversity of bacteria in the rumen of dairy cows. FEMS Microbiol. Ecol. 78:275-284. https://doi.org/10.1111/j.1574-6941.2011.01154.x.

Hugenholtz, P., S. D. Hooper, and N. C. Kyrpides. 2009. Focus: Synergistetes. Environ. Microbiol. 11:1327-1329. https://doi. org/10.1111/j.1462-2920.2009.01949.x.

Humer, E., K. Ghareeb, H. Harder, E. Mickdam, A. Khol-Parisini, and Q. Zebeli. 2015. Peripartal changes in reticuloruminal pH and temperature in dairy cows differing in the susceptibility to subacute rumen acidosis. J. Dairy Sci. 98:8788-8799. https://doi. org/10.3168/jds.2015-9893.

Indikova, I., T. J. Humphrey, and F. Hilbert. 2015. Survival with a helping hand: Campylobacter and microbiota. Front. Microbiol. 6:1266. https://doi.org/10.3389/fmicb.2015.01266.

Jiao, J., J. Huang, C. Zhou, and Z. Tan. 2015. Taxonomic identification of ruminal epithelial bacterial diversity during rumen development in goats. Appl. Environ. Microbiol. 81:3502-3509. https:// doi.org/10.1128/AEM.00203-15.

Joachimiak, M. P., J. L. Weisman, and B. May. 2006. JColorGrid: Software for the visualization of biological measurements. BMC Bioinformatics 7:225. https://doi.org/10.1186/1471-2105-7-225.

Jouany, J. P. 2006. Optimizing rumen functions in the close-up transition period and early lactation to drive dry matter intake and energy balance in cows. Anim. Reprod. Sci. 96:250-264. https:// doi.org/10.1016/j.anireprosci.2006.08.005.

Kallus, S. J., and L. J. Brandt. 2012. The intestinal microbiota and obesity. J. Clin. Gastroenterol. 46:16-24. https://doi.org/10.1097/ MCG.0b013e31823711fd.

Kampmann, K., S. Ratering, I. Kramer, M. Schmidt, W. Zerr, and S. Schnell. 2012. Unexpected stability of Bacteroidetes and Firmicutes communities in laboratory biogas reactors fed with different defined substrates. Appl. Environ. Microbiol. 78:2106-2119. https://doi.org/10.1128/AEM.06394-11.

Kamra, D. N. 2005. Rumen microbial ecosystem. Curr. Sci. 89:124135 .

Khafipour, E., J. C. Plaizier, P. C. Aikman, and D. O. Krause. 2011. Population structure of rumen Escherichia coli associated with subacute ruminal acidosis (SARA) in dairy cattle. J. Dairy Sci. 94:351-360. https://doi.org/10.3168/jds.2010-3435.

Klevenhusen, F., P. Pourazad, S. U. Wetzels, M. Qumar, A. KholParisini, and Q. Zebeli. 2014. Technical note: Evaluation of a real-time wireless $\mathrm{pH}$ measurement system relative to intraruminal differences of digesta in dairy cattle. J. Anim. Sci. 92:5635-5639. https://doi.org/10.2527/jas.2014-8038.

Kozich, J. J., S. L. Westcott, N. T. Baxter, S. K. Highlander, and P. D. Schloss. 2013. Development of a dual-index sequencing strategy and curation pipeline for analyzing amplicon sequence data on the MiSeq Illumina sequencing platform. Appl. Environ. Microbiol. 79:5112-5120. https://doi.org/10.1128/AEM.01043-13.

Leonhard-Marek, S., G. Breves, and R. Busche. 2006. Effect of chloride on $\mathrm{pH}$ microclimate and electrogenic $\mathrm{Na}^{+}$absorption across the rumen epithelium of goat and sheep. Am. J. Physiol. Gas- trointest. Liver Physiol. 291:G246-G252. https://doi.org/10.1152/ ajpgi.00419.2005.

Li, M., G. B. Penner, E. Hernandez-Sanabria, M. Oba, and L. L. Guan. 2009. Effects of sampling location and time, and host animal on assessment of bacterial diversity and fermentation parameters in the bovine rumen. J. Appl. Microbiol. 107:1924-1934. https://doi. org/10.1111/j.1365-2672.2009.04376.x.

Lien, T., M. Madsen, I. H. Steen, and K. Gjerdevik. 1998. Desulfobulbus rhabdoformis sp. nov., a sulfate reducer from a water-oil separation system. Int. J. Syst. Bacteriol. 48:469-474. https://doi. org/10.1099/00207713-48-2-469.

Lin, M., W. Guo, Q. Meng, D. M. Stevenson, P. J. Weimer, and D. M. Schaefer. 2013. Changes in rumen bacterial community composition in steers in response to dietary nitrate. Appl. Microbiol. Biotechnol. 97:8719-8727. https://doi.org/10.1007/s00253-0135143-z.

Liu, J. H., M. L. Zhang, R. Y. Zhang, W. Y. Zhu, and S. Y. Mao. 2016. Comparative studies of the composition of bacterial microbiota associated with the ruminal content, ruminal epithelium and in the faeces of lactating dairy cows. Microb. Biotechnol. 9:257-268. https://doi.org/10.1111/1751-7915.12345.

Mackie, R. I. 2000. Molecular ecology and diversity in gut microbial ecosystems. Pages 61-77 in Ruminant Physiology: Digestion, Metabolism, Growth and Reproduction. P. B. Cronje, ed. CABI, Wallingford, UK.

Mao, S., M. Zhang, J. Liu, and W. Zhu. 2015. Characterising the bacterial microbiota across the gastrointestinal tracts of dairy cattle: Membership and potential function. Sci. Rep. 5:16116 https://doi. org $/ 10.1038 /$ srep16116.

Mao, S. Y., R. Y. Zhang, D. S. Wang, and W. Y. Zhu. 2013. Impact of subacute ruminal acidosis (SARA) adaptation on rumen microbiota in dairy cattle using pyrosequencing. Anaerobe 24:12-19. https://doi.org/10.1016/j.anaerobe.2013.08.003.

McCann, J. C., S. Luan, F. C. Cardoso, H. Derakhshani, E. Khafipour, and J. J. Loor. 2016. Induction of subacute ruminal acidosis affects the ruminal microbiome and epithelium. Front. Microbiol. 7:701. https://doi.org/10.3389/fmicb.2016.00701.

McCowan, R. P., K. J. Cheng, C. B. M. Bailey, and J. W. Costerton. 1978. Adhesion of bacteria to epithelial-cell surfaces within reticulo-rumen of cattle. Appl. Environ. Microbiol. 35:149-155.

Mohammed, R., D. M. Stevenson, P. J. Weimer, G. B. Penner, and K. A. Beauchemin. 2012. Individual animal variability in ruminal bacterial communities and ruminal acidosis in primiparous Holstein cows during the periparturient period. J. Dairy Sci. 95:67166730. https://doi.org/10.3168/jds.2012-5772

Murphy, C., C. Carroll, and K. N. Jordan. 2003. Induction of an adaptive tolerance response in the foodborne pathogen, Campylobacter jejuni. FEMS Microbiol. Lett. 223:89-93.

Penner, G. B., K. A. Beauchemin, and T. Mutsvangwa. 2007. Severity of ruminal acidosis in primiparous Holstein cows during the periparturient period. J. Dairy Sci. 90:365-375. https://doi. org/10.3168/jds.S0022-0302(07)72638-3.

Penner, G. B., M. A. Steele, J. R. Aschenbach, and B. W. McBride. 2011. Ruminant nutrition symposium: molecular adaptation of ruminal epithelia to highly fermentable diets. J. Anim. Sci. 89:1108 1119. https://doi.org/10.2527/jas.2010-3378.

Plaizier, J. C., E. Khafipour, S. Li, G. N. Gozho, and D. O. Krause 2012. Subacute ruminal acidosis (SARA), endotoxins and health consequences. Anim. Feed Sci. Technol. 172:9-21. https://doi. org/10.1016/j.anifeedsci.2011.12.004.

Plaizier, J. C., D. O. Krause, G. N. Gozho, and B. W. McBride. 2008. Subacute ruminal acidosis in dairy cows: the physiological causes, incidence and consequences. Vet. J. 176:21-31. https://doi. org/10.1016/j.tvj1.2007.12.016.

Pourazad, P., R. Khiaosa-Ard, M. Qumar, S. U. Wetzels, F. Klevenhusen, B. Metzler-Zebeli, and Q. Zebeli. 2016. Transient feeding of a concentrate-rich diet increases the severity of subacute ruminal acidosis in dairy cattle. J. Anim. Sci. 94:726-738. https://doi. org/10.2527/jas.2015-9605.

Pruesse, E., C. Quast, K. Knittel, B. M. Fuchs, W. Ludwig, J. Peplies, and F. O. Glockner. 2007. SILVA: A comprehensive online resource 
for quality checked and aligned ribosomal RNA sequence data compatible with ARB. Nucleic Acids Res. 35:7188-7196. https:// doi.org/10.1093/nar/gkm864.

R Development Core Team. 2015. A Language and Environment for Statistical Computing. Version 3.1.3. R Foundation for Statistical Computing, Vienna, Austria.

Robertson, C. E., J. K. Harris, B. D. Wagner, D. Granger, K. Browne, B. Tatem, L. M. Feazel, K. Park, N. R. Pace, and D. N. Frank. 2013. Explicet: Graphical user interface software for metadatadriven management, analysis and visualization of microbiome data. Bioinformatics 29:3100-3101. https://doi.org/10.1093/ bioinformatics/btt526.

Russell, J. B., and D. B. Wilson. 1996. Why are ruminal cellulolytic bacteria unable to digest cellulose at low $\mathrm{pH}$ ? J. Dairy Sci 79:1503-1509. https://doi.org/10.3168/jds.S0022-0302(96)765104.

Sato, S. 2016. Pathophysiological evaluation of subacute ruminal acidosis (SARA) by continuous ruminal pH monitoring. Anim. Sci. J. 87:168-177. https://doi.org/10.1111/asj.12415.

Schlau, N., L. L. Guan, and M. Oba. 2012. The relationship between rumen acidosis resistance and expression of genes involved in regulation of intracellular $\mathrm{pH}$ and butyrate metabolism of ruminal epithelial cells in steers. J. Dairy Sci. 95:5866-5875. https://doi. org/10.3168/jds.2011-5167.

Steele, M. A., G. B. Penner, F. Chaucheyras-Durand, and L. Guan. 2016. Development and physiology of the rumen and the lower gut: Targets for improving gut health. J. Dairy Sci. 99:4955-4966. https://doi.org/10.3168/jds.2015-10351.

Tamaki, H., C. L. Wright, X. Li, Q. Lin, C. Hwang, S. Wang, J. Thimmapuram, Y. Kamagata, and W. T. Liu. 2011. Analysis of $16 \mathrm{~S}$ rRNA amplicon sequencing options on the Roche/454 next-generation titanium sequencing platform. PLoS One 6:e25263. https:// doi.org/10.1371/journal.pone.0025263.

Wallace, R. J., K. J. Cheng, D. Dinsdale, and E. R. Orskov. 1979. An independent microbial flora of the epithelium and its role in the ecomicrobiology of the rumen. Nature 279:424-426.

Weimer, P. J. 2015. Redundancy, resilience, and host specificity of the ruminal microbiota: Implications for engineering improved ruminal fermentations. Front. Microbiol. 6:296. https://doi.org/10.3389/ fmicb.2015.00296.

Weimer, P. J., D. M. Stevenson, H. C. Mantovani, and S. L. Man. 2010. Host specificity of the ruminal bacterial community in the dairy cow following near-total exchange of ruminal contents. J. Dairy Sci. 93:5902-5912. https://doi.org/10.3168/jds.2010-3500.
Wetzels, S. U., E. Mann, B. U. Metzler-Zebeli, P. Pourazad, M. Qumar, F. Klevenhusen, B. Pinior, M. Wagner, Q. Zebeli, and S. SchmitzEsser. 2016. Epimural indicator phylotypes of transiently-induced subacute ruminal acidosis in dairy cattle. Front. Microbiol. 7:274. https://doi.org/10.3389/fmicb.2016.00274.

Wetzels, S. U., E. Mann, B. U. Metzler-Zebeli, M. Wagner, F. Klevenhusen, Q. Zebeli, and S. Schmitz-Esser. 2015. Pyrosequencing reveals shifts in the bacterial epimural community relative to dietary concentrate amount in goats. J. Dairy Sci. 98:5572-5587. https:// doi.org/10.3168/jds.2014-9166.

Yin, Y. Y., Y. J. Liu, W. Y. Zhu, and S. Y. Mao. 2014. Effects of acarbose addition on ruminal bacterial microbiota, lipopolysaccharide levels and fermentation characteristics in vitro. AsianAustralas. J. Anim. Sci. 27:1726-1735. https://doi.org/10.5713/ ajas.2014.14292.

Zakrzewski, M., A. Goesmann, S. Jaenicke, S. Junemann, F. Eikmeyer, R. Szczepanowski, W. A. Al-Soud, S. Sorensen, A. Puhler, and A. Schluter. 2012. Profiling of the metabolically active community from a production-scale biogas plant by means of high-throughput metatranscriptome sequencing. J. Biotechnol. 158:248-258. https://doi.org/10.1016/j.jbiotec.2012.01.020.

Zebeli, Q., J. R. Aschenbach, M. Tafaj, J. Boguhn, B. N. Ametaj, and W. Drochner. 2012. Invited review: Role of physically effective fiber and estimation of dietary fiber adequacy in high-producing dairy cattle. J. Dairy Sci. 95:1041-1056. https://doi.org/10.3168/ jds.2011-4421.

Zebeli, Q., J. Dijkstra, M. Tafaj, H. Steingass, B. N. Ametaj, and W. Drochner. 2008. Modeling the adequacy of dietary fiber in dairy cows based on the responses of ruminal $\mathrm{pH}$ and milk fat production to composition of the diet. J. Dairy Sci. 91:2046-2066. https://doi.org/10.3168/jds.2007-0572.

Zebeli, Q., and B. U. Metzler-Zebeli. 2012. Interplay between rumen digestive disorders and diet-induced inflammation in dairy cattle. Res. Vet. Sci. 93:1099-1108. https://doi.org/10.1016/j. rvsc.2012.02.004

Zhao, L., Q. X. Meng, L. P. Ren, W. Liu, X. Z. Zhang, Y. L. Huo, and Z. M. Zhou. 2015. Effects of nitrate addition on rumen fermentation, bacterial biodiversity and abundance. Asian-Australas. J. Anim. Sci. 28:1433-1441. https://doi.org/10.5713/ajas.15.0091.

Zhao, S., J. Wang, and D. Bu. 2014. Pyrosequencing-based profiling of bacterial 16S rRNA genes identifies the unique Proteobacteria attached to the rumen epithelium of bovines. J. Dairy Sci. 97(ESuppl. 1):869-870. (Abstr.) 